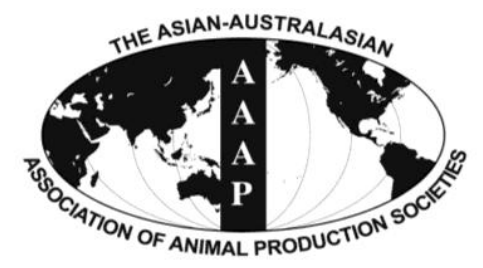

Asian-Aust. J. Anim. Sci.

Vol. 25, No. 6 : 751 - 757

June 2012

www.ajas.info

http://dx.doi.org/10.5713/ajas.2011.11331

\title{
Molecular Characterization of Selected Local and Exotic Cattle Using RAPD Marker
}

\author{
M. Mahfuza Khatun ${ }^{1,2}, *$, Khondoker Moazzem Hossain ${ }^{1}$ and S. M. Mahbubur Rahman ${ }^{1}$ \\ ${ }^{1}$ Biotechnology and Genetic Engineering Discipline, Khulna University, Khulna-9208, Bangladesh
}

\begin{abstract}
In order to develop specific genetic markers and determine the genetic diversity of Bangladeshi native cattle (Pabna, Red Chittagong) and exotic breeds (Sahiwal), randomly amplified polymorphic DNA (RAPD) analysis was performed using 12 primers. Genomic DNA was extracted from 20 cattle (local and exotic) blood samples and extracted DNA was observed by gel electrophoresis. Among the random primers three were matched and found to be polymorphic. Genetic relations between cattle's were determined by RAPD polymorphisms from a total of $66.67 \%$. Statistical analysis of the data, estimating the genetic distances between cattle and sketching the cluster trees were estimated by using MEGA 5.05 software. Comparatively highest genetic distance (0.834) was found between RCC-82 and SL-623. The lowest genetic distance (0.031) was observed between M-1222 and M-5730. The genetic diversity of Red Chittagong and Sahiwal cattle was relatively higher for a prescribed breed. Adequate diversity in performance and adaptability can be exploited from the study results for actual improvement accruing to conservation and development of indigenous cattle resources. (Key Words: RAPD-PCR, Genetic Distance, Polymorphism, Cattle, Bangladesh)
\end{abstract}

\section{INTRODUCTION}

Cattle are the most common type of large domesticated ungulates of the subfamily Bovinae and belong to the genus Bos. Generally, cattle are raised as livestock for meat, milk leather, dung and draft purposes. It has been estimated that there were 1.3 billion cattle in the world (Bruford et al., 2003) whereas Bangladesh had 24 million cattle, out of which 6 million were dairy cattle of local and crossbreds (Bhuiyan, 1993). The available breeds in Bangladesh are Red Chittagong, local Pabna, Sahiwal cross breed, Holstein Frisian cross breeds etc. It is speculated that the Red Chittagong evolved through interbreeding among the local cattle on the basis of natural selection. Sahiwal are a breed of zebu cattle, primarily used in dairy production, from the Sahiwal district of Pakistan, a dry region of Punjab which lies along the Indian-Pakistani border (Mason, 1996). The Bangladeshi indigenous cattle breed (Pabna) and Red Chittagong breed, are of particular importance because of their favorable meat, milk, leather and draft quality

\footnotetext{
* Corresponding Author: M. Mahfuza Khatun. Tel: 86-411-8470 6308, Fax: 86-411-84706329, E-mail: oni.ku.bd@ gmail.com

${ }^{2}$ School of Life Science and Biotechnology, Dalian University of Technology, Dalian City, Liaoning Province, China. Submitted Sept. 11, 2011; Accepted Nov. 6, 2011; Revised Jan. 22, 2012
}

although their productivity is relatively low in general. Dairying is considered a strong tool to develop village micro economy in Bangladesh (Shamsuddin et al., 2006) to improve rural livelihoods and to alleviate rural poverty. But, like other developing countries, breed substitution and crossbreeding programs have been practiced indiscriminately in Bangladesh for many years with exotic breeds and as a result valuable genetic resources are being lost or diluted.

Genetic diversity or similarity can be measured through genetic markers. These have been used to determine evolutionary relationships within and between species, genera or higher taxonomic categories (Cornuet et al., 1999). RAPD markers, generated by the Polymerase Chain Reaction (PCR) have been widely used since the 1990's to assess intra-specific genetic variation at the nuclear level (Garrigan et al., 2002). This procedure detects nucleotide sequence polymorphisms in a DNA amplification-based assay using only a single primer of an arbitrary nucleotide sequence. The polymorphism between individuals results from sequence differences in one or both of the primer binding sites and is visible as the presence or absence of a particular RAPD band. Therefore, in order to determine the genetic variability of selective native, exotic and cross cattle populations of Bangladesh, the research was undertaken 
using RAPD-PCR.

\section{MATERIALS AND METHODS}

\section{Animal selection, blood sample collection and extraction of genomic DNA}

The experiment was carried out at the Animal Cell Culture and Molecular Biology Laboratory, Biotechnology and Genetic Engineering Discipline, Khulna University, Khulna-9208, Bangladesh during the period of November 2010 to May 2011. A total of 20 cattle were selected for this study, in which five were native Pabna (M-1222, M-5730, M-1893, LF-1414, M-1980), ten native Red Chittagong (RCC-5730， RCC-178， RCC-175， RCC-609， RCC-80, RCC-173, RCC-81, RCC-691, RCC-82, RCC-77) and five exotic Sahiwal (SL-571, SL-614, SL-623, SL-637, SL-638) cattle from Bangladesh Livestock Research Institute, Dhaka. Three $\mathrm{ml}$ of blood was collected from each animal in a $5 \mathrm{ml}$ EDTA vaccutainer. The blood was gently mixed with EDTA (present in the vacationer) and kept at $-20^{\circ} \mathrm{C}$ until the study start. Genomic DNA was extracted from blood samples following the method described by Roe et al. (1996) with some modifications. About $800 \mu \mathrm{l}$ of blood was taken in a microcentrifuge tube and the cell membrane disrupted with 1X Standard Saline Citrate (SSC) buffer. Then the protein was precipitated by sodium acetate and digested with proteinase $\mathrm{K}$ at $55^{\circ} \mathrm{C}$ for $1 \mathrm{~h}$. After that, the aqueous layer was removed by Phenol:Chloroform:Isoamyl alcohol (25:24:1) and precipitated with $100 \%$ ethanol. DNA was reprecipitated and washed with $\mathrm{Na}$ acetate and $70 \%$ ice cold ethanol. Finally DNA samples were dried and dissolved in TE buffer and stored at $-20^{\circ} \mathrm{C}$ for further use.

Gel documentation, DNA quantification and PCR amplification

Presence of extracted DNA was confirmed by gel electrophoresis separation on $1 \%$ agarose gel and staining with ethidium bromide. Ultraviolet (UV) spectrophotometer set at $260 \mathrm{~nm}$ was used to quantify the DNA concentration prior to PCR. The PCR amplification conditions were set according to Williams et al. (1990). Primers were selected mainly based on GC content, intensity of bands, presence of smearing, consistency within individuals and potential for population discrimination. Primers that have GC content more than $60 \%$ are suitable for RAPD analysis. We selected twelve subsets of primers supplied by Bioneer, South Korea. PCR was carried out in MyGenie 96 thermal block, Bioneer, South Korea. PCR amplification followed the method of Simon et al. (2007). The PCR reaction was carried out in a final volume of $20 \mu \mathrm{l}$ reaction mixture containing $2 \mu \mathrm{l}$ of template (4ng DNA), $2 \mu \mathrm{l}$ of $10 \times$ reaction buffer, $2 \mu \mathrm{l}$ of dNTPs (250 mM each), 2 units of Taq DNA polymerase, 1 $\mu \mathrm{l}(100$ picomol $)$ of primer and $11 \mu \mathrm{l}$ of sterile distilled water, respectively. The mixture was over layered with a drop of mineral oil. The PCR amplification conditions were: PCR lead at $105^{\circ} \mathrm{C}$, hot start at $94^{\circ} \mathrm{C}$ for 4 min's, denaturation at $94^{\circ} \mathrm{C}$ for $1 \mathrm{~min}$, annealing at $35^{\circ} \mathrm{C}$ for $1 \mathrm{~min}$, extension at $72^{\circ} \mathrm{C}$ for 2 min's, 35 cycles, final extension at $72^{\circ} \mathrm{C}$ for $10 \mathrm{~min}$, holding at $4^{\circ} \mathrm{C}$ for $10 \mathrm{~min}$ and end.

\section{Agarose gel electrophoresis and data analysis}

Amplified PCR products were electrophoresised (Agaro-power system, Bioneer Corporation, South Korea) on an agarose gel (2\%) in TAE buffer and visualized by staining with ethidium bromide solution. Polymorphic bands were observed by high performance UV transilluminator (UVP-UK) and pictures were taken by GEL DOC/Bio-Imaging System affiliated digital canon camera. In the study of genetic diversity, each germplasm was scored manually for presence or absence of a particular amplification product. Data was analyzed by the software GelQuest and MEGA5.05 for phylogenic analysis. RAPD matrix of the 20 cattle samples using OPA07, OPA03 and OPA09 primers were assembled for statistical analysis and the sizes of the DNA fragments were estimated using 100 bp ladders by co-electrophoresis with the PCR product DNA. The un-weighted pair group method with arithmetic averages (UPGMA) based dendrogram was constructed using the MEGA5.05. Numerical values were considered to construct the dendogram and presence of band (1) and absence of band (0) value considered for RAPD analysis. All possible pair-wise genetic distances were calculated according to Nei and $\mathrm{Li}$ (1979) using the following formula: $\mathrm{d}_{\mathrm{xy}}=1-\left(2 \mathrm{n}_{\mathrm{xy}} /\left(\mathrm{n}_{\mathrm{x}}+\mathrm{n}_{\mathrm{y}}\right)\right)$, Where, $\mathrm{n}_{\mathrm{x}}$ and $\mathrm{n}_{\mathrm{y}}$ are the numbers of bands amplified in individuals $x$ and y respectively and $2 n_{x y}$ is the number of bands shared by those individuals. In this analysis, smaller numbers are associated with more genetically similar individuals, whereas larger numbers suggest genetically dissimilarity.

\section{RESULT AND DISCUSSION}

The experimental cattle showed variability in genetical characteristics and the results indicated the effectiveness of RAPD analysis in detecting the level of polymorphism. Randomly 12 primers were tested among them three primers (Table 1) were matched and found polymorphic (Figures 1, 2 and 3).

From the figures, it was observed that primer OPA-03 and OPA-07 were more reproducible and produced a more

Table 1. List of primers those showed polymorphism

\begin{tabular}{clc}
\hline Primer no. & \multicolumn{1}{c}{ Sequence $\left(5^{\prime}-3^{\prime}\right)$} & $(\mathrm{G}+\mathrm{C})$ Contents \% \\
\hline OPA-03 & TGCCTCGCACCA & 66.7 \\
OPA-07 & GGTGACGCAG & 70 \\
OPA-09 & GTTGCCACCC & 70 \\
\hline
\end{tabular}


distinct RAPD profile than primer OPA-09. Three different primers generated various banding patterns and out of the 21 bands scored, 14 bands $(66.67 \%)$ were found to be polymorphic and 7 bands $(33.33 \%)$ were found to be monomorphic in nature. Different RAPD patterns generated using the primers in the present experiment are shown in Figure 1 to 3.

Table 2 shows that the frequencies of polymorphic bands varied from primer to primer in which primer OPA03, OPA-07 and OPA-09 produced 80\%, 42.85\% and $75 \%$ polymorphic loci respectively. Primer OPA-03 produced 10 bands where one at $400 \mathrm{bp}$ and the other $700 \mathrm{bp}$ were monomorphic in all samples. The polymorphic fragments for primer OPA-03 ranged from $900 \mathrm{bp}$ to 2,000 bp. Furthermore, primer OPA-07 and OPA-09 produced 7 and 4 bands, respectively. The range of monomorphic bands for

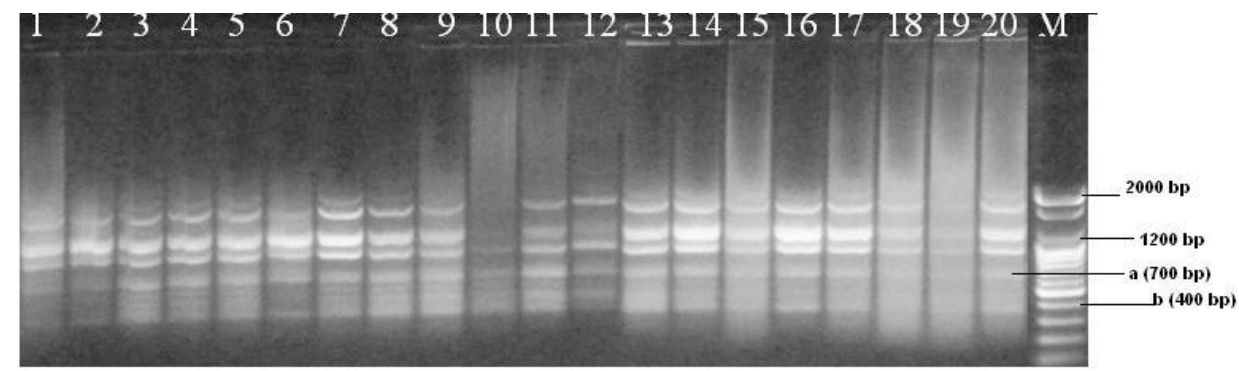

Figure 1. RAPD profiles using primer OPA-03. The number corresponds to the serial of the genotypes; M is a 100 bp DNA ladder. ' $a$ ' and ' $b$ ' bands were monomorphic for all the experimental animals.

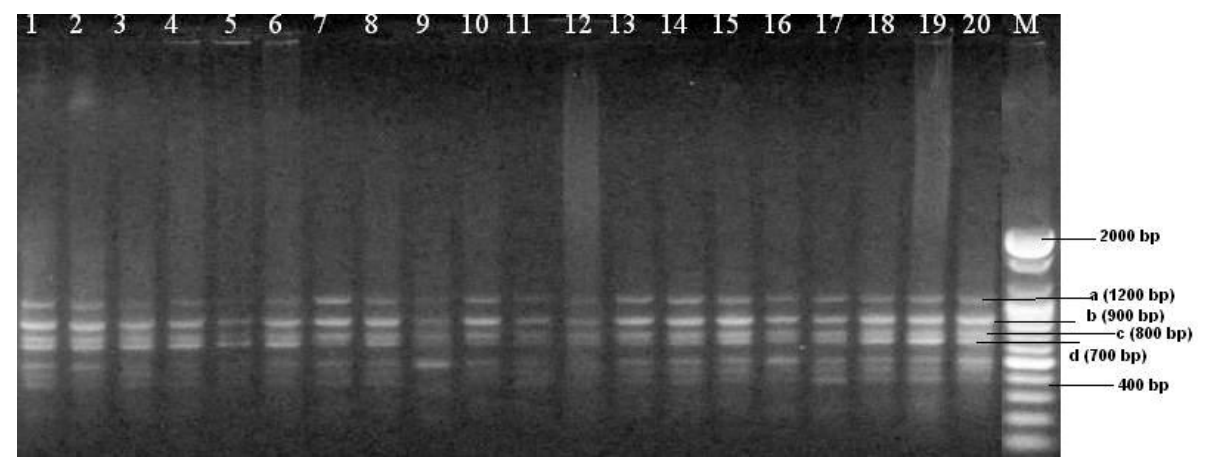

Figure 2. RAPD profiles using primer OPA-07. On the gel 'a', 'b', 'c' and'd' bands were monomorphic for all experimental animals.

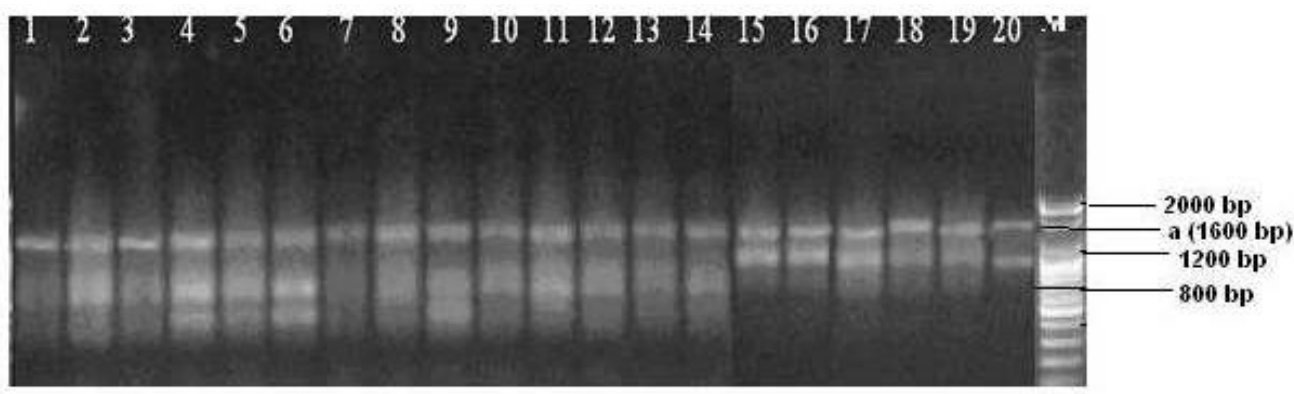

Figure 3. RAPD profiles using primer OPA-09. ' $a$ ' is monomorphic for all experimental animals.

Table 2. List of primers and their monomorphic and polymorphic bands

\begin{tabular}{lcccccc}
\hline Primer code & $\begin{array}{c}\text { No. of } \\
\text { bands }\end{array}$ & $\begin{array}{c}\text { No. of } \\
\text { monomorphic } \\
\text { bands }\end{array}$ & $\begin{array}{c}\text { Size of } \\
\text { monomorphic } \\
\text { bands (bp) }\end{array}$ & $\begin{array}{c}\text { No. of } \\
\text { polymorphic } \\
\text { bands }\end{array}$ & $\begin{array}{c}\text { Size of } \\
\text { polymorphic bands } \\
\text { (bp) }\end{array}$ & Polymorphism (\%) \\
\hline OPA-03 & 10 & 2 & $700-400$ & 8 & $2,000-900$ & 80 \\
OPA-07 & 7 & 4 & $1,000-700$ & 3 & $600-400$ & 42.85 \\
OPA-09 & 4 & 1 & 1,600 & 3 & $1,200-800$ & 75 \\
Total $=3$ & 21 & 7 & $33.33 \%$ & 14 & & 66.67 \\
\hline
\end{tabular}


primer OPA-07 and OPA-09 were 700 bp to 1,000 bp, 1,600 $\mathrm{bp}$, respectively. Where as, the range of polymorphic bands were $400 \mathrm{bp}$ to $600 \mathrm{bp}$ and $800 \mathrm{bp}$ to $1,200 \mathrm{bp}$, respectively. As the number of bands common in all animals produced by primer OPA-07 was (4) greater than the other two primers (2 for OPA-03 and 1 for OPA-09), it can be concluded that OPA-07 may be specific for species or for greater zoological classes (gender, family etc.). This point needs to be clarified in the future by a comparison with other species. Sharma et al. (2009) reported, the size of polymorphic bands ranged between $200 \mathrm{bp}$ and 2,500 bp using 17 operon series random primers to characterize the Malvi and Sahiwal breeds of cattle in Madhya Pradesh, India. In another study involving indigenous African cattle, Gwakisa et al. (1994) used RAPD markers to characterize the local Zebu (Bos indicus) cattle breeds of Tanzania (using ILO 1127 primer) and showed 61\% polymorphism which are almost similar to the present study. The degree of polymorphism $66.67 \%$ is higher compared to $28 \%$ in taurine cattle (Talle et al., 2005) and $18 \%$ in zebu cattle (Marle-Koster et al., 2003). Estimation of higher level of genetic variation in the breeds might be consistent with the fact that they are highly polymorphic animals. Polymorphisms at the level of individual, breed, species or gender can be produced by RAPD-PCR but it is difficult to identify the bands. No breed- or sex-specific RAPD bands were detected in this study. Nevertheless, by mean of their monomorphic band profiles, some of the investigated primers can give the information that animals not having these monomorphic bands may not be related to these cattle. More studies should be performed on this matter in comparative genome studies.

\section{Pair wise genetic distance}

From the Table 3 it can be found that the highest value of Nei and Li's (1979) genetic distance (0.834) was between SL-623 and RCC-82. Lower estimates of genetic similarities indicated a high degree of genetic diversity between these two cattle. This may be due to their diverse origin and different purpose of raising these cattle. On the other hand, the lowest distance (0.031) existed between M5730 and $M-1222$. It indicates, the genetic relationship between local cattle population was closer than others. Sharma et al. (2009) calculated between breed band sharing (BS), the value for these 2 breeds obtained was lower $(0.43$ to 0.66 ) than within breed BS value, which was 0.70 to 0.93 in Malvi breed and 0.68 to 0.88 in Sahiwal breed, found similar genetic distances of average animals like the present experiment.

The present results revealed that there was a high level of genetic variaton among the studied cattle as indicated by the proportion of polymorphic loci. The values of pair-wise genetic distance among 20 cattle genotypes were computed from combined data sets for the 3 primers ranging from 0.834 to 0.031 (Table 3). Kemp and Teale (1994) identified population-specific DNA polymorphisms to detect Bos indicus and Bos taurus in West Africa. They estimated the allele frequency characteristics of cattle breeds using DNA markers (Buitcamp et al., 1991; Mannen and Tsuji, 1993; Glowatzki-Mullis et al., 1995; Choy et al., 2001). Heterozygosity estimates obtained for the Burlina breed were moderate to high and consistent to the value reported

Table 3. Estimation of pair wise genetic distance between experimental cattle populations using Nei and Li's (1979) equation

\begin{tabular}{|c|c|c|c|c|c|c|c|c|c|c|c|c|c|c|c|c|c|c|c|c|}
\hline $\begin{array}{c}\text { Tag } \\
\text { No. }\end{array}$ & $\begin{array}{c}\text { RCC- } \\
173\end{array}$ & $\begin{array}{c}\text { RCC- } \\
178\end{array}$ & $\begin{array}{c}\text { RCC- } \\
691\end{array}$ & $\begin{array}{c}\text { RCC- } \\
175\end{array}$ & $\begin{array}{c}\text { RCC- } \\
609\end{array}$ & $\begin{array}{c}\text { RCC- } \\
77\end{array}$ & $\begin{array}{c}\text { RCC- } \\
78\end{array}$ & $\begin{array}{c}\text { RCC- } \\
80\end{array}$ & $\begin{array}{c}\text { RCC- } \\
81\end{array}$ & $\begin{array}{c}\text { RCC- } \\
82\end{array}$ & $\begin{array}{l}\text { SL- } \\
571\end{array}$ & $\begin{array}{l}\text { SL- } \\
614\end{array}$ & $\begin{array}{l}\text { SL- } \\
623\end{array}$ & $\begin{array}{l}\text { SL- } \\
637\end{array}$ & $\begin{array}{l}\text { SL- } \\
638\end{array}$ & $\begin{array}{c}\text { M- } \\
1222\end{array}$ & $\begin{array}{c}\text { LF- } \\
1414\end{array}$ & $\begin{array}{c}\text { M- } \\
1893\end{array}$ & $\begin{array}{c}\text { M- } \\
1980\end{array}$ & $\begin{array}{c}\text { M- } \\
5730\end{array}$ \\
\hline 1 & $* * *$ & & & & & & & & & & & & & & & & & & & \\
\hline 2 & 0.164 & $* * *$ & & & & & & & & & & & & & & & & & & \\
\hline 3 & 0.111 & 0.241 & $* * *$ & & & & & & & & & & & & & & & & & \\
\hline 4 & 0.259 & 0.172 & 0.181 & $* * *$ & & & & & & & & & & & & & & & & \\
\hline 5 & 0.185 & 0.185 & 0.393 & 0.217 & $* * *$ & & & & & & & & & & & & & & & \\
\hline 6 & 0.185 & 0.185 & 0.304 & 0.111 & 0.200 & $* * *$ & & & & & & & & & & & & & & \\
\hline 7 & 0.142 & 0.142 & 0.217 & 0.111 & 0.133 & 0.696 & $* * *$ & & & & & & & & & & & & & \\
\hline 8 & 0.259 & 0.214 & 0.304 & 0.214 & 0.032 & 0.125 & 0.259 & $* * *$ & & & & & & & & & & & & \\
\hline 9 & 0.185 & 0.214 & 0.533 & 0.214 & 0.133 & 0.307 & 0.333 & 0.666 & $* * *$ & & & & & & & & & & & \\
\hline 10 & 0.214 & 0.142 & 0.304 & 0.214 & 0.161 & 0.096 & 0.230 & 0.161 & 0.241 & $* * *$ & & & & & & & & & & \\
\hline 11 & 0.071 & 0.103 & 0.333 & 0.285 & 0.803 & 0.096 & 0.153 & 0.360 & 0.172 & 0.032 & $* * *$ & & & & & & & & & \\
\hline 12 & 0.111 & 0.142 & 0.185 & 0.172 & 0.133 & 0.033 & 0.142 & 0.133 & 0.066 & 0.200 & 0.333 & $* * *$ & & & & & & & & \\
\hline 13 & 0.111 & 0.142 & 0.185 & 0.714 & 0.133 & 0.200 & 0.172 & 0.133 & 0.344 & 0.834 & 0.230 & 0.200 & $* * *$ & & & & & & & \\
\hline 14 & 0.142 & 0.214 & 0.142 & 0.142 & 0.133 & 0.602 & 0.172 & 0.062 & 0.133 & 0.230 & 0.153 & 0.307 & 0.238 & $* * *$ & & & & & & \\
\hline 15 & 0.071 & 0.172 & 0.143 & 0.640 & 0.200 & 0.230 & 0.241 & 0.043 & 0.333 & 0.386 & 0.214 & 0.346 & 0.230 & 0.814 & $* * *$ & & & & & \\
\hline 16 & 0.142 & 0.103 & 0.142 & 0.142 & 0.096 & 0.386 & 0.066 & 0.142 & 0.103 & 0.161 & 0.172 & 0.161 & 0.230 & 0.083 & 0.200 & $* * *$ & & & & \\
\hline 17 & 0.142 & 0.103 & 0.142 & 0.103 & 0.161 & 0.384 & 0.200 & 0.142 & 0.103 & 0.307 & 0.060 & 0.307 & 0.214 & 0.172 & 0.200 & 0.360 & $* * *$ & & & \\
\hline 18 & 0.185 & 0.200 & 0.172 & 0.241 & 0.161 & 0.307 & 0.200 & 0.214 & 0.096 & 0.185 & 0.142 & 0.259 & 0.172 & 0.241 & 0.032 & 0.133 & 0.033 & $* * *$ & & \\
\hline 19 & 0.103 & 0.572 & 0.148 & 0.066 & 0.217 & 0.185 & 0.200 & 0.103 & 0.062 & 0.538 & 0.111 & 0.230 & 0.083 & 0.066 & 0.066 & 0.133 & 0.142 & 0.035 & $* * *$ & \\
\hline 20 & 0.172 & 0.040 & 0.103 & 0.133 & 0.062 & 0.153 & 0.032 & 0.160 & 0.111 & 0.259 & 0.200 & 0.259 & 0.214 & 0.200 & 0.161 & 0.031 & 0.062 & 0.142 & 0.214 & $* * *$ \\
\hline
\end{tabular}


by Del Bo et al. (2001) that found an estimate of 0.68 . However, such variability represents an important reservoir of genetic diversity that should be conserved. Genetic diversity is in fact important to allow genetic improvement in selected breeds as well as to facilitate rapid adaptation.

\section{Dendrogram analysis}

Estimation of genetic similarity within and between cattle and genetic distance among different cattle is an important application of the DNA based genetic markers. Dendrogram stability is an important aspect to be considered in genetic variability studies. An unweighted pair-group method of analysis (UPGMA) phylogenic tree based on genetic distance using the MEGA software (version 5.05) is shown in Figure 4. Dendogram depicted the relationship among twenty population of RCC, Sahiwal and local cattle. The dendogram segregated the twenty cattle into two major clusters: (I) and (II). Cluster I sub divided into IA and IB. Furthermore, cluster IA subclustered into IA (1) and IA (2). On the other hand, cluster IB subdivided into IB (1) and IB (2).

Subcluster IA comprised of RCC-609, RCC-80, SL-637, SL-623, RCC-175, RCC-178, M-1222, M-5730 and RCC78 cattle population and subcluster IB consisted of RCC173, M-1980, RCC-691, RCC-81, M-1893, LF-1414 and SL-638 cattle population. On the other hand, cluster II belong cattle RCC-82, SL-571, SL-614 and RCC-77. From the dendogram, closely related indigenous population e.g., RCC and SL co-existed in cluster II might be due to their same origin as well as lower genetic variability. Whereas, local Pabna and RCC randomly segregated between subcluster IB and Cluster IA. The possible reasons for their random segregation could be the indiscriminate breeding/crossing, migration of animals, mutation in ancestors or due to different origin.

Moreover, the long genetic distance between SL-623 and local RCC-82 indicates that they can be crossed for parent development. The highest genetic diversity is alarming as it indicates that the population may deteriorate due to crossing with other populations of either native or exotic blood. In another similar study, Yu et al. (2004) used RAPD analysis to estimate genetic diversity and relationship of two native cattle breeds from the Yunnan province of China (De Hong cattle and Di Qing cattle) and four introduced beef cattle breeds (Brahman, Simmental, Murry Grey, and Short Horn). Using 10 primers, it was observed that the Yunnnan DeHong cattle breed was closely related to the Brahman (Bos indicus), and the Yunnan DiQing cattle breed was closely related to the Simmental, short horn, and Murry grey (Bos taurus) breeds. It is reported that uncontrolled hybridizations are increasing and the phylogenic relationship of the RCC and Local Pabna cattle is close because regional animal cooperative systems have been using RCC bulls for breeding programs since 1995 (Ahmed, 2000).

The high level of polymorphism obtained by the present study indicates that RAPD markers could be considered as effective tools for estimating genetic diversity in

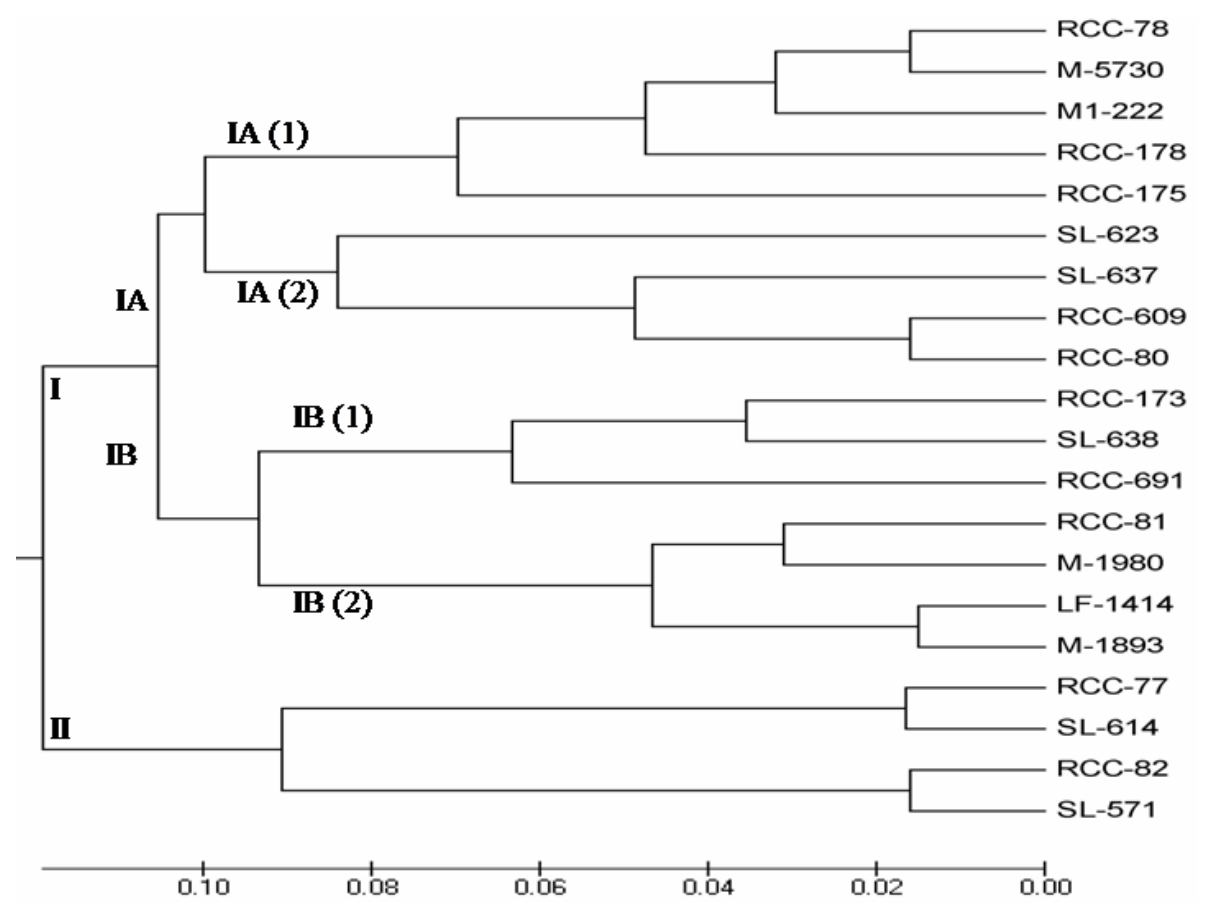

Figure 4. The unweighted pair group method of analysis (UPGMA) dendrogram based on summarized data regarding differentiation among experimental cattle. 
experimental cattle populations. For a more efficient determination of genetic diversity in cattle varieties, a higher number of decamer primers showing a maximum number of polymorphic band or other available marker systems could be utilized. Nevertheless, if the markers developed in the present experimental animals can be linked with quantitative trait loci for economically important traits, they could be used successfully in future breeding and germplasm conservation programs for cattle production systems of Bangladesh.

\section{CONCLUSION}

This study demonstrated that the short random oligonucleotides of arbitrary sequences can be used to successfully differentiate cattle by variation of RAPD fingerprints in breed-specific DNA pools and subsequently can be used to produce prominent fingerprints in individual animals. The polymorphism of the experimental cattle was $66.67 \%$ and suggests that the gene segregation rate has recently increased in these animals. The genetic variation in the experimental cattle populations was high and therefore, there is scope of selective breeding (like ONBS) for future improvement of Red Chittagong, Sahiwal and local cattle. Gradual genetic erosion and extinction is threatening an increasing number of animal species; the major consequence being a loss of global genetic diversity. Sets of genetic markers are required to identify distinct populations so that they can be preserved. The local Bangladeshi Pabna cattle and Red Chittagong cattle are of particular importance because of their favourable meat, milk, leather and draft quality although their productivity is relatively low in general. Like other developing countries, breed substitution and crossbreeding programs with exotic breeds have been practiced indiscriminately in Bangladesh for many years and as a result valuable genetic resources are being lost or diluted. In addition, genetic assessment is also of interest for the design of genetic improvement programs including appropriate choice of breeds for crossbreeding. Thus, it is important to identify molecular characteristics of these breed/populations for undertaking proper breeding programmes and conservation strategy.

\section{REFERENCES}

Bhuiyan, A. K. F. H. 1993. Livestock research database for Bangladesh. Funded by USAID. Bangladesh Agricultural Research Council (BARC), Dhaka, Bangladesh.

Bruford, M. W., D. G. Bradley and G. Luikart. 2003. DNA markers reveal the complexity of livestock domestication. Nat. Rev. Genet. 4(11):900-910.

Buitcamp, J., H. Zischler, J. T. Epplen and H. Geldermann. 1991. DNA fingerprinting in cattle using oligonucleotide probe. Anim. Genet. 22:137.
Choy, Y. H., S. J. Oh and J. O. Kang. 2001. Application of RAPD methods in meat for beef breed identification. Asian-Aust. J. Anim. Sci. 14:1655-1658.

Cornuet, J. M., S. Piry, G. Luikart, A. Estoup and M. Sloignac. 1999. New methods employing multilocus genotypes to select or exclude populations as origins of individuals. Genetics 153: 1989-2000.

Bo, L. D., M. Polli, M. Longeri, G. Cerotti, C. Looft, A. BarreDirie, G. Dolf and M. Zanotti. 2001. Genetic diversity among some cattle breeds in the Alpine area. J. Anim. Breed. Genet. 118:317-325.

Garrigan, D., P. C. Marsh and T. E. Dowling. 2002. Long-term effective population size of three endangered Colorado River fishes. Anim. Conserv. 5:95-102.

Glowatzki-Mullis, C., G. Gaillard, G. Wigger and R. Fries. 1995. Microsatellite based on parentage control in cattle. Anim. Genet. 26:7-12.

Gwakisa, P. S., S. J. Kemp and A. J. Teale. 1994. Characterization of Zebu cattle breeds in Tanzania using Random Amplified Polymorphic DNA markers. Anim. Genet. 25:89-94.

Hassen, F., E. Bekele, W. Ayalew and T. Dessie. 2007. Genetic variability of five Indigenous Ethiopian cattle breeds using RAPD markers. Afr. J. Biotechnol. 6:2274-2279.

Kantanen, J., J. Vilkki, K. Elo and A. Maki-Tanila. 1995. Random amplified polymorphic DNA in cattle and sheep: application for detecting genetic variation. Anim. Genet. 26:315-320.

Kemp, S. J. and A. J. Teale. 1994. Characterization of Zebu cattle breeds in Tanzania using Random Amplified Polymorphic DNA markers. Anim. Genet. 25:89-94.

Mannen, H. and S. Tsuji. 1993. DNA fingerprinting for individual identification and parentage test in Japanese Black cattle using five different mini-and one microsatellite probes. J. Anim. Genet. 21:62-68.

Marle-Koster, E. and L. H. Van-Nel. 2003. Genetic markers and their application in livestock breeding in South Africa. S. Afr. J. Anim. Sci. 33:1-10.

Mason, I. L. 1996. A world dictionary of livestock breeds, types and varieties. Fourth Edition. C.A.B International, p. 273.

Mbulu, D. N. and O. Hannotte. 2005. Comparative genetic analysis of molecular diversity of African cattle. In: The Role of Biotechnology. Tulin, Italy.

Mufti, M. M. R., M. P. Mostari, G. K. Deb, K. Nahar and K. S. Huque. 2009. Genetic diversity of red Chittagong cattle using Randomly Amplified Polymorphic DNA markers. American Journal of Animal and Veterinary Sciences 4:1-5.

Nei, M. and W. H. Li. 1979. Mathematical model for studying genetic variation in terms of restriction endonucleases. Proc. Natl. Acad. Sci. USA 76:5269-5273.

Roe, B. A., J. Crabtree and A. Khan. 1996. DNA isolation and sequencing: Essential techniques series, D. Rickwood, Ed., J. Wiley and Sons New York.

Shamsuddin, M., W. J. Goodger, M. S. Hossein, T. Azizunnesa, Bennett and T. Nordlund. 2006. A survey to identify economic opportunities for smallholder dairy farms in Bangladesh. Trop. Anim. Health Prod. 38:131-140.

Sharma, M., S. Singh, A. Kushwah and B. C. Sarkhel. 2009. Molecular characterization of Malvi and Sahiwal breed of cattle by RAPD-PCR. Indian J. Anim. Sci. 79:44-46.

Simon, L., S. Shyamalamma and P. Narayanaswamy. 2007. 
Morphological and molecular analysis of Genetic diversity in Jackfruit. J. Hortic. Sci. Biotechnol. 82:764-768.

Talle, S. B., W. S. Chenyabuga, E. Fimland, O. Syrstad, T. Meuwissen and H. Klungland. 2005. Use of DNA technologies for the conservation of animal genetic resources. Acta Agric. Scand. Section A-Animal. 55:1-8.
Williams, J. G. K., A. R. Kubelik, K. J. Livak, J. A. Rafalski and S. V. Tingey. 1990. DNA polymorphisms amplified by arbitrary primers are useful as genetic markers. Nucleic. Acids Res. 18:6531-6535. 